\title{
Modeling and Optimizing of Producing Recycled PET from Fabrics Waste via Falling Film-Rotating Disk Combined Reactor
}

\author{
Dan Qin,, ${ }^{1}$ Chaosheng Wang, ${ }^{1}$ Huaping Wang, ${ }^{1}$ Ye Chen, ${ }^{1}$ Peng Ji, ${ }^{2}$ and Zhenhao Xi ${ }^{3}$ \\ ${ }^{1}$ State Key Laboratory for Modification of Chemical Fibers and Polymer Materials, College of Materials Science and Engineering, \\ Donghua University, Shanghai 201620, China \\ ${ }^{2}$ Co-Innovation Center for Textile Industry, Donghua University, Shanghai 201620, China \\ ${ }^{3}$ Shanghai Key Laboratory of Multiphase Materials Chemical Engineering, East China University of Science and Technology, \\ Shanghai 200237, China \\ Correspondence should be addressed to Chaosheng Wang; cswang@dhu.edu.cn
}

Received 22 May 2017; Accepted 25 July 2017; Published 26 September 2017

Academic Editor: Nobuhiro Kawatsuki

Copyright (C) 2017 Dan Qin et al. This is an open access article distributed under the Creative Commons Attribution License, which permits unrestricted use, distribution, and reproduction in any medium, provided the original work is properly cited.

\begin{abstract}
Recycling and reusing of poly (ethylene terephthalate) (PET) fabrics waste are essential for reducing serious waste of resources and environmental pollution caused by low utilization rate. The liquid-phase polymerization method has advantages of short process flow, low energy consumption, and low production cost. However, unlike prepolymer, the material characteristics of PET fabrics waste (complex composition, high intrinsic viscosity, and large quality fluctuations) make its recycling a technique challenge. In this study, the falling film-rotating disk combined reactor is proposed, and the continuous liquid-phase polymerization is modeled by optimizing and correcting existing models for the final stage of PET polymerization to improve the product quality in plant production. Through modeling and simulation, the weight analysis of indexes closely related to the product quality (intrinsic viscosity, carboxyl end group concentration, and diethylene glycol content) was investigated to optimize the production process in order to obtain the desired polymer properties and meet specific product material characteristics. The model could be applied to other PET wastes (e.g., bottles and films) and extended to investigate different aspects of the recycling process.
\end{abstract}

\section{Introduction}

Polyethylene terephthalate (PET) is widely used in fibers and as an engineering plastic owing to its excellent properties [13]. A great proportion of PET production is for fibers (about $60 \%$ ) [4], and PET fabrics account for a large fraction of the whole fiber materials (more than 50\%) [5]. PET waste is not suitable for landfills due to environmental pollution caused by its nonbiodegradable nature [6,7], although it accounts for more than $8 \%$ by weight (and $12 \%$ by volume) of the world's solid waste [8]. However, the utilization rate of PET fabrics waste is not satisfactory, resulting in wasted resources and serious pollution. Therefore, recycling and utilizing PET fabrics waste are essential for realizing sustainable development in the chemical fiber and textile industries [9].

The methods for recycling PET waste are mainly divided into physical and chemical ones. In the physical method, the fabrics waste is prepared into filling or packaging materials after a simple opening process. This technique has been basically eliminated, however, since the products are low in quality. In the chemical recycling method, the first stage is degrading the polymer into small molecules, mainly through hydrolysis [10, 11], methanolysis [12, 13], glycolysis [14, 15], and aminolysis $[16,17]$, followed by purification and conversion into useful chemical products [18, 19]. However, the high cost, extensive energy consumption, and complex process of this technology limit its application in large-scale production. In the physical-chemical method, the material is processed with liquid or solid-phase polymerization, which increases the molecular weight and extracts volatile small molecules. This method can effectively improve the quality of recycled products and realize differential recycling without significantly increasing the production costs. Compared to solidphase polymerization (SSP), in the alternative method of liquid-phase polymerization, the produced PET melt could be directly used for spinning, bypassing the need for melting 
after pelleting, which has reduced energy consumption and lowered production cost, and it also avoids further thermal degradation reaction to preserve the product quality in largescale production.

The liquid-phase polymerization is commonly used in the final stage of polymerization from low molecular weight prepolymer (e.g., degree of polymerization $\left(\mathrm{DP}_{n}\right)=$ 20-30, carboxyl end group concentration $([\mathrm{COOH}])=$ $60-80 \mathrm{mmol} / \mathrm{kg}$ ) to produce conventional PET (e.g., $\mathrm{DP}_{n}=$ 100 , carboxyl end group concentration $([\mathrm{COOH}])=$ 20-35 mmol $/ \mathrm{kg}$ ). In contrast, the composition of PET fabrics waste is complex (including dyes, auxiliaries, and additives) with large quality fluctuations. The characteristics of PET fabrics waste $\left(\mathrm{DP}_{n}=60-90,[\mathrm{COOH}]=25-45 \mathrm{mmol} / \mathrm{kg}\right)$ make it quite different from the prepolymer. The traditional industrial reactor for liquid-phase polymerization is the horizontal reactor equipped with rotating disk agitators $[20,21]$. However, these reactors suffer from many problems, such as limited surface area, poor flow condition at the border, and a large amount of dead zones [22, 23]. The characteristics of PET waste mentioned above make the devolatilization process difficult, limit the forward polymerization reaction, cause serious thermal degradation in the melt processing, and have higher requirements in the reactor construction.

The quality of recycled PET is influenced by several factors, such as the equipment, raw material characteristics, and process conditions. To find the main factors and optimize the product quality, the suitable model is needed for the continuous liquid-phase polymerization of PET fabrics waste. There have been several efforts to model the liquid-phase polymerization using prepolymer with low molecular weight [24-26] in order to guide and optimize production. Laubriet et al. [27] proposed a two-phase model (melt and vapor phases) to simulate the final polymerization process of PET. Kim et al. [28] extended the two-phase model to a multizone finishing reactor consisting of two rotating disk reactors using a prepolymer with low $\mathrm{DP}_{n}$ as the feed and compared their results with factory data. The accuracy of this model was limited to that of the molecular weight at the second outlet, which may be suitable for conventional PET due to its simple composition and consistent quality. To further improve the quality of recycled PET, the more relevant indexes should be by taken into account PET fabrics waste.

In practice, three product characteristics are essential in recycled PET, namely, intrinsic viscosity (IV), carboxyl end group concentration $([\mathrm{COOH}])$, and diethylene glycol content ([DEG]). IV is correlated with the molecular weight. Without an appropriate IV, the spun fibers can easily break and seriously lower the product quality. The carboxyl end group concentration determines the thermal, thermooxidation, and hydrolytic stability during processing and the color of the product [27]. A high [COOH] would accelerate PET degradation and leads to the more levels of carboxyl end group formation [29], the reduction of molecular weight, and breakage of the filaments during spinning. The DEG content influences the crystallization, but it improves the rate and uniformity of dyeing [30,31]. Therefore, it is preferred to have a certain amount of DEG content to meet the demand for different products.

This work proposes a novel combined reactor setup for PET fabrics waste. To improve the quality of recycled PET and meet specific product characteristics in practical production, the continuous liquid-phase polymerization in the reactor was modeled by optimizing and correcting existing models for the final stage of PET polymerization. The weight analysis of three indexes closely related to the quality of recycled PET (intrinsic viscosity, carboxyl end group concentration, and diethylene glycol content) was conducted based on the modeling and simulation, so as to determine the optimal process parameters, obtain the desired polymer properties, and provide useful reference for industrial production.

\section{Experiments and Methods}

The raw material (provided by Ningbo Dafa Chemical Fiber Co., Ltd., China) was PET fabrics waste after friction hot forming, which lowers the bulk density and facilitates the processing. The liquid-phase polymerization process was carried out in the falling film-rotating disk combined reactor at the same company. The gas chromatographymass spectrometry (GC-MS) analysis was carried out on a Shimadzu (QP 2010) series analysis instrument (Japan) to analyze the composition of vacuum extraction in the process. The polydispersity index (PDI) was acquired with a PL-GPC50 gel permeation chromatograph. Samples were dissolved and filtered in $98: 2 \mathrm{w} / \mathrm{w}$ hexafluoroisopropanol (HFIP) : chloroform, with a concentration of $2 \mathrm{mg} / \mathrm{mL}$ [32].

\section{Large-Scale Continuous Liquid Polymerization Model}

3.1. Reaction Scheme. The polymer segment and functional groups were used to model the liquid-phase polymerization reaction $[25,33]$. The prefix " $T$ " is used to denote end groups, and prefix "B" stands for repeated groups. T-EG, T-TPA, T-DEG, and T-VIN refer to the end groups of hydroxyl, carboxyl, diethylene glycol, and vinyl, respectively. The volatile small molecules are ethylene glycol (EG), water (W), diethylene glycol (DEG), and acetaldehyde (AA). The segment approach for the polymerization kinetic scheme and the kinetic rate constant is shown in Tables 1 and 2. The main reactions considered during the liquid-phase polymerization include esterification/hydrolysis, interesterification/alcoholysis, thermal degradation, and the formation of DEG and AA. The reactions to form cyclic polymers are not considered in our model. There is no extra catalyst added in this process. However, the $\mathrm{Sb}$ concentration in the PET waste was measured $(0.21 \mathrm{mg} / \mathrm{g})$ and converted into the equivalent amount of conventional $\mathrm{Sb}_{2} \mathrm{O}_{3}$ catalyst $(0.025 \mathrm{wt} \%)$ to account for its effect on the liquid-phase polymerization.

3.2. Falling Film-Rotating Disk Combined Reactor. As seen in Figure 1, in the falling film reactor, the PET melt after the screw melting flows through the multiple layers from the top to the bottom without agitation, in order to generate 
TABLE 1: Kinetic scheme [27].

\begin{tabular}{lccc}
\hline Reaction & Equation & \multicolumn{2}{c}{ Rate constant } \\
& FG + T-TPA $\rightleftharpoons$ T-EG + B-TPA + W & $k_{1}$ & $K_{1}$ \\
Esterification & T-EG + T-TPA $\rightleftharpoons$ B-EG + B-TPA + W & $k_{2}$ & $K_{2}$ \\
Polycondensation & T-EG + T-EG $\rightleftharpoons$ B-EG + EG & $k_{3}$ & $K_{3}$ \\
Thermal degradation & B-TPA + B-EG $\longrightarrow$ T-VIN + T-TPA & $k_{4}$ & - \\
& B-TPA + T-EG + EG $\longrightarrow$ DEG + T-TPA & $k_{5}$ & - \\
Diethylene glycol formation & B-TPA + T-EG + T-EG $\longrightarrow$ T-DEG + T-TPA & $k_{6}$ & - \\
& T-EG + T-DEG $\rightleftharpoons$ B-EG + DEG & $k_{7}$ & $k_{7} / K_{7}$ \\
Acetaldehyde formation & B-TPA + T-EG $\longrightarrow$ T-TPA + AA & $k_{8}$ & - \\
\hline
\end{tabular}

TABLE 2: Kinetic rate constants [27, 34, 35].

\begin{tabular}{lccc}
\hline & \multicolumn{3}{c}{ Rate constant $^{\mathrm{a}}$} \\
$\begin{array}{l}\text { Reactions } \\
\text { number }\end{array}$ & $k_{i}=A_{i} \times\left(\mathrm{Cat}^{*} / 0.05\right) \times \exp \left(-E_{i} / \mathrm{RT}\right)$ & $K_{i}$ \\
& $A_{i}$ & $\begin{array}{c}E_{i} \\
(\mathrm{kcal} / \mathrm{kmol})\end{array}$ \\
\hline 1 & $2.08 \times 10^{6}\left(\mathrm{~L} \mathrm{~mol}^{-1} \mathrm{~min}^{-1}\right)$ & 17.6 & 2.5 \\
2 & $2.08 \times 10^{6}\left(\mathrm{~L} \mathrm{~mol}^{-1} \mathrm{~min}^{-1}\right)$ & 17.6 & 1.25 \\
3 & $1.36 \times 10^{6}\left(\mathrm{~L} \mathrm{~mol}^{-1} \mathrm{~min}^{-1}\right)$ & 18.5 & 0.5 \\
4 & $7.2 \times 10^{9}\left(\mathrm{~min}^{-1}\right)^{\mathrm{b}}$ & 37.8 & \\
5 & $8.32 \times 10^{7}\left(\mathrm{~L} \mathrm{~mol}^{-1} \mathrm{~min}^{-1}\right)$ & 29.8 & \\
6 & $8.32 \times 10^{7}\left(\mathrm{~L} \mathrm{~mol}^{-1} \mathrm{~min}^{-1}\right)$ & 29.8 & \\
7 & $1.36 \times 10^{6}\left(\mathrm{~L} \mathrm{~mol}^{-1} \mathrm{~min}^{-1}\right)$ & 18.5 & 1.0 \\
8 & $8.32 \times 10^{7}\left(\mathrm{~min}^{-1}\right)$ & 29.8 & \\
9 & $1.36 \times 10^{6}\left(\mathrm{~L} \mathrm{~mol}^{-1} \mathrm{~min}^{-1}\right)$ & 18.5 & \\
\hline
\end{tabular}

${ }^{a}$ Catalyst $\left(\mathrm{Sb}_{2} \mathrm{O}_{3}\right)$ concentration $=0.05 \mathrm{wt} \%$ and Cat ${ }^{*}$ is the concentration used in our work. ${ }^{\mathrm{b}}$ The optimized value in our work is $1.36 \times 10^{10}$.

large volatilization areas for removing small molecules at high temperature and high vacuum. Each grid consisting of several stainless steel bars could be regarded as a layer and the adjacent grids are in a staggered arrangement. PET melt flows through the slits on each grid to form falling films. The volatile small molecules are removed from the liquidphase through the thin surface film, thereby increasing the molecular weight of the polymer and the viscosity along the axial direction. The width of the slits in each grid and the gap between layers could be adjusted to control the quality indexes according to the material characteristics and product application. This design could achieve a controllable and structured flow field. The small molecule products are also removed during the process and proceed through cyclone separator and dust filter for condensation and filtration. The PET melt that passes through the last layer is either directly sent to the spinning process or fed continuously into a second rotating disk reactor for further liquid-phase polymerization. After the second reactor, the produced melt with good fluidity and high homogeneity under stirring could also be used for spinning [37]. Taken together, the flexible serial reactors could realize various combinations (e.g., falling film-falling film and rotating disk-rotating disk reactors) to adjust to the raw material characteristics and the intended product application, allowing different PET wastes (e.g., bottle flakes, fabrics, and films) to be processed on a large scale.

3.3. Reactor Modeling. The flow of the bulk melt phase was assumed to be plug flow and the vapor phase was assumed to be perfectly mixed. The falling film reactor should be divided into different sections (length ratio $1: 1: 1.22: 1.22: 1.47$ ) according to the size of slits and the number of grids, which are directly associated with the gas-liquid interfacial areas as shown in Figure 2. The modeling equations for the liquidphase is listed in Table 3 , where $\theta$ is the mean residence time for the $i$ th section, $z$ is the dimensionless distance from the reactor inlet, and $\left[\mathrm{EG}^{*}\right]$ is the equilibrium concentration of EG at the gas-liquid interface. Due to its high vapor pressure at the reaction temperature, $\mathrm{AA}$ is considered as removed immediately. The mass transfer parameter $k_{\mathrm{L}} \alpha$ is used for the other three small molecules [27]. $k_{\mathrm{L}} \alpha$ is closely related to reactor geometry not with the sections and two values were used for the different structure of the two reactors. The equilibrium interfacial concentration and the molar fraction of the volatile species are given by (1) [30,36]. To better represent the real process, the melt after the screw is selected as the feed stream for the mixed raw material waste used in practice. The moisture content in the PET waste is controlled below $70 \mathrm{ppm}$ to avoid serious hydrolysis. The segment fractions for T-TPA, B-TPA, T-EG, B-EG, B-DEG, and T-VIN of the feed stream are 0.00404, 0.493, 0.00793, $0.484,0.0107$, and 0.00033 , respectively. The total flow is $2750 \mathrm{~kg} / \mathrm{h}$.

$$
\begin{aligned}
& C_{j}^{*}=\left(\frac{C_{\mathrm{PET}}}{1-\sum_{j} x_{j}^{*}}\right) x_{j}^{*} ; \quad x_{j}^{*}=\frac{P y_{j}}{P_{j}^{0} \gamma_{j}} j=\mathrm{EG}, \mathrm{W}, \mathrm{DEG} \\
& y_{j} \\
& =\frac{\int_{0}^{1}\left(k_{\mathrm{L}} \alpha\right)_{j}\left(C_{j}-C_{j}^{*}\right) d z}{\sum_{j} \int_{0}^{1}\left(k_{\mathrm{L}} \alpha\right)_{j}\left(C_{j}-C_{j}^{*}\right) d z+\int_{0}^{1}\left(k_{8} C_{1}+k_{9} C_{1} C_{6}\right) d z} .
\end{aligned}
$$




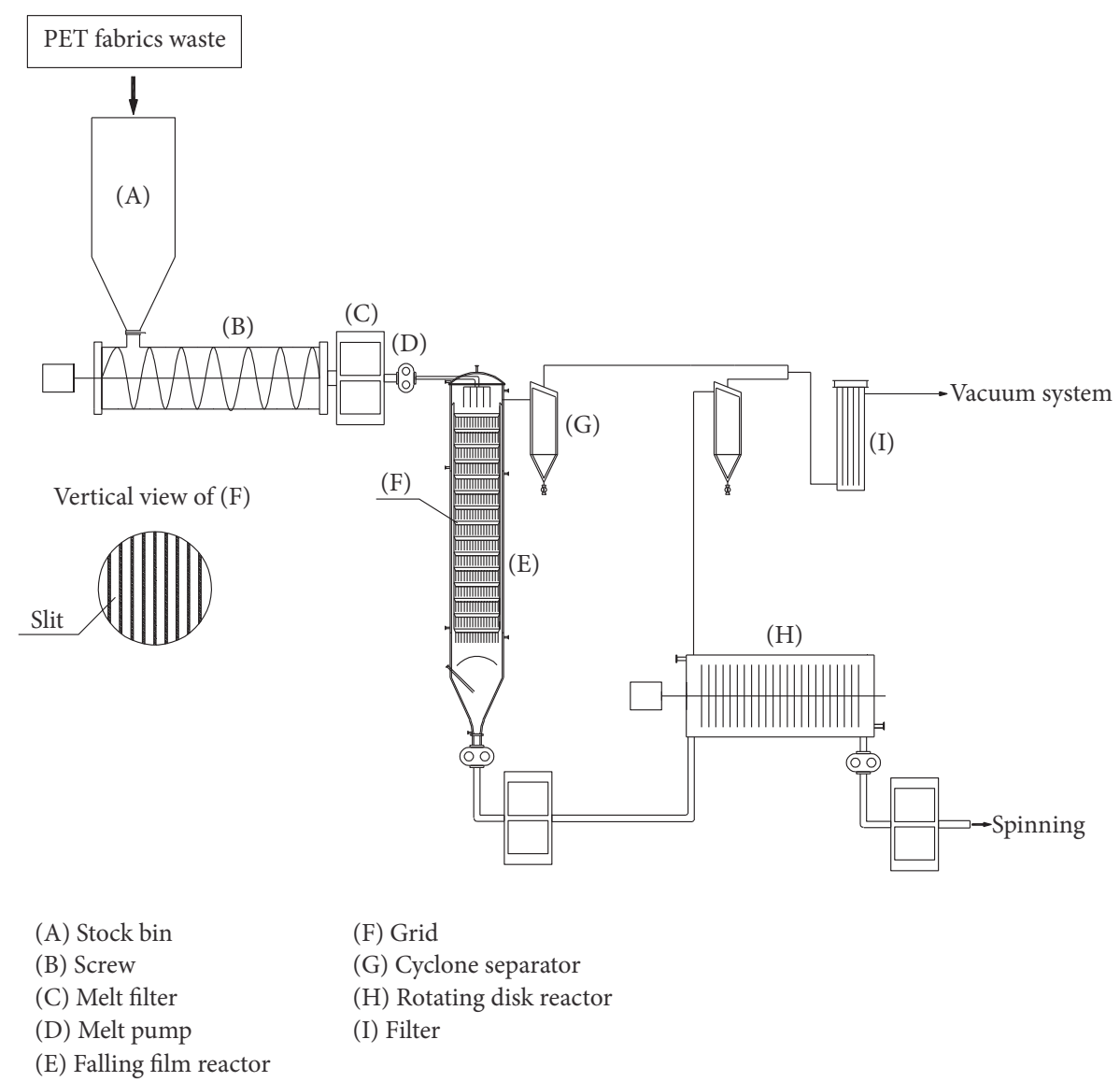

FIGURE 1: Schematic of the falling film-rotating disk combined reactor.

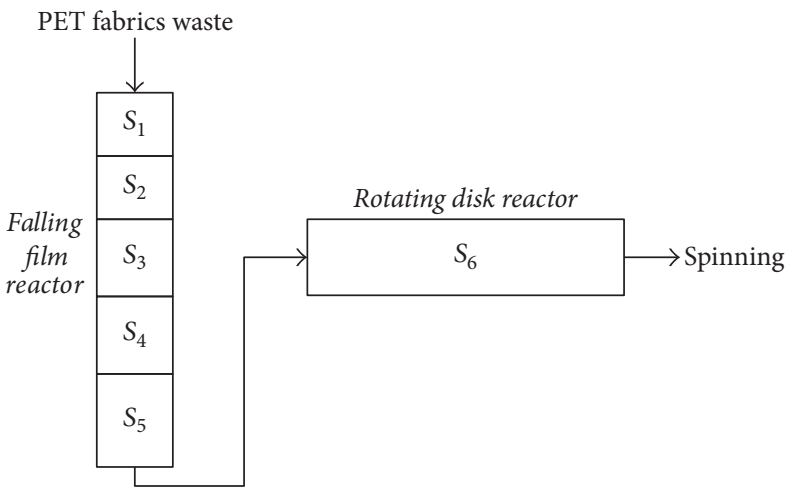

FIGURE 2: Schematic of the falling film-rotating disk combined reactor with multiple sections.

\section{Results and Discussion}

4.1. Combination of the Reactors. It is possible to establish the relationship between the quality indexes in our model and the product characteristics in actual production [35]. The formulas are shown as follows, where $\mathrm{DP}_{n}$ is the degree of polymerization, $f$ is the molar flow rate of the segment, and $M_{\mathrm{DEG}}$ is 106.12. The test value of [DEG] includes all forms of diethylene glycol and $f_{\mathrm{DEG}}$ is marked as the sum of B-DEG,TDEG, and free DEG molar flow in our model for simplicity.

$$
\begin{aligned}
\operatorname{IV}(\mathrm{dL} / \mathrm{g})= & 2.1 \times 10^{4} \\
& \times\left(192.17 \times \mathrm{DP}_{n}\right)^{0.82} \\
{[\mathrm{COOH}](\mathrm{mmol} / \mathrm{kg})=} & \frac{f_{\mathrm{T}-\mathrm{TPA}} \times 10^{6}}{\text { Liquid mass flow rate }} \\
{[\mathrm{DEG}](\%)=} & \frac{f_{\mathrm{DEG}} \times M_{\mathrm{DEG}} \times 10^{2}}{\text { Liquid mass flow rate }} .
\end{aligned}
$$

Different reactor configurations were used in the actual production to determine the best approach for PET fabrics waste, as shown in Figure 3. The interfacial area in the traditional rotating disk reactor is limited, while the configuration of falling film reactor was found to provide large interfacial area for mass transfer [23]. Therefore, the single falling film reactor works much better than the rotating disk one. The use of two reactors further offers increased flexibility and work better when applied appropriately. When the first reactor is the rotating disk reactor instead of the falling film one, the smaller interfacial area leads to PET melt with higher $[\mathrm{COOH}]$ and lower molecular weight. This is detrimental to the liquid-phase polymerization in the second reactor, for the high carboxyl end group concentration would accelerate PET 
TABLE 3: Model equations used in this study $[28,36]$.

$\frac{1}{\theta_{i}} \frac{d C_{1 i}}{d z}=R_{1 i}-R_{2 i}-2 R_{3 i}-R_{5 i}-2 R_{6 i}-R_{7 i}-R_{8 i}-R_{9 i}$

$\frac{1}{\theta} \frac{d C_{2 i}}{d z}=-R_{1 i}-R_{2 i}+R_{4 i}+R_{5 i}+R_{6 i}+R_{8 i}$

$\frac{1}{\theta_{i}} \frac{d C_{3 i}}{d z}=R_{2 i}+R_{3 i}-R_{4 i}+R_{7 i}+R_{9 i}$

$\frac{1}{\theta_{i}} \frac{d C_{4 i}}{d z}=R_{1 i}+R_{2 i}-R_{4 i}-R_{5 i}-R_{6 i}-R_{8 i}$

$\frac{1}{\theta_{i}} \frac{d C_{5 i}}{d z}=R_{6 i}-R_{7 i}$

$\frac{1}{\theta_{i}} \frac{d C_{6 i}}{d z}=R_{4 i}-R_{9 i}$

$\frac{1}{\theta_{i}} \frac{d C_{7 i}}{d z}=-R_{1 i}+R_{3 i}-R_{5 i}-\left(k_{\mathrm{L}} \alpha_{i}\right)\left([\mathrm{EG}]-[\mathrm{EG}]^{*}\right)$

$\frac{1}{\theta_{i}} \frac{d C_{8 i}}{d z}=R_{1 i}+R_{2 i}-\left(k_{\mathrm{L}} \alpha_{i}\right)\left([\mathrm{W}]-[\mathrm{W}]^{*}\right)$

$\frac{1}{\theta_{i}} \frac{d C_{9 i}}{d z}=R_{5 i}+R_{7 i}-\left(k_{\mathrm{L}} \alpha_{i}\right)\left([\mathrm{DEG}]-[\mathrm{DEG}]^{*}\right)$

$\frac{1}{\theta_{i}} \frac{d C_{10 i}}{d z}=R_{8 i}+R_{9 i}$

Where:

$R_{1}=2 k_{1} C_{7} C_{2}-\left(\frac{k_{1}}{K_{1}}\right) C_{4} C_{8}$

$R_{2}=2 k_{2} C_{1} C_{2}-\left(\frac{k_{2}}{K_{2}}\right) C_{4} C_{8}$

$R_{3}=k_{3} C_{1}^{2}-4\left(\frac{k_{3}}{K_{3}}\right) C_{3} C_{7}$

$R_{4}=\frac{k_{4} C_{3} C_{4}}{\left(C_{1}+C_{3}\right)}$

$R_{5}=k_{5} C_{1} C_{7}$

$R_{6}=k_{6} C_{1}^{2}$

$R_{7}=k_{7} C_{1} C_{5}-4\left(\frac{k_{7}}{K_{7}}\right) C_{3} C_{9}$

$R_{8}=k_{8} C_{1}$

$R_{9}=k_{9} C_{1} C_{6}$

$C_{1}-C_{10}$ is the concentration of T-EG, T-TPA, B-EG, B-TPA, T-DEG, T-VIN, EG, W, DEG, and AA, respectively.

degradation [29]. The product with lower $\mathrm{DP}_{n}$ and higher $[\mathrm{COOH}]$ is obtained in the combination of rotating diskfalling film reactor, compared with falling film-rotating disk combination. Therefore, the first reactor should be the falling film one. The combination of rotating disks-rotating disk reactors works worse than the other combined reactors.

The performance of the falling film reactor is closely connected with the size of slits and the number of grids. PET melt cannot flow through small slits with increasing viscosity and a longer residence time with smaller slits reduces the quality of recycled PET for the melt flows only relies on the gravity flow in the falling film reactor. But larger slits reduce the interfacial area closely related to the liquid polymerization, all of which cause problems in both liquid polymerization effect and implementation process in the actual production. Therefore, the configuration of the first falling film could not be used as the second one and the combination of two falling film reactors is not shown here. In the second rotating disk reactor, the polymerization process and residence time could be controlled to a certain extent by optimizing the agitator

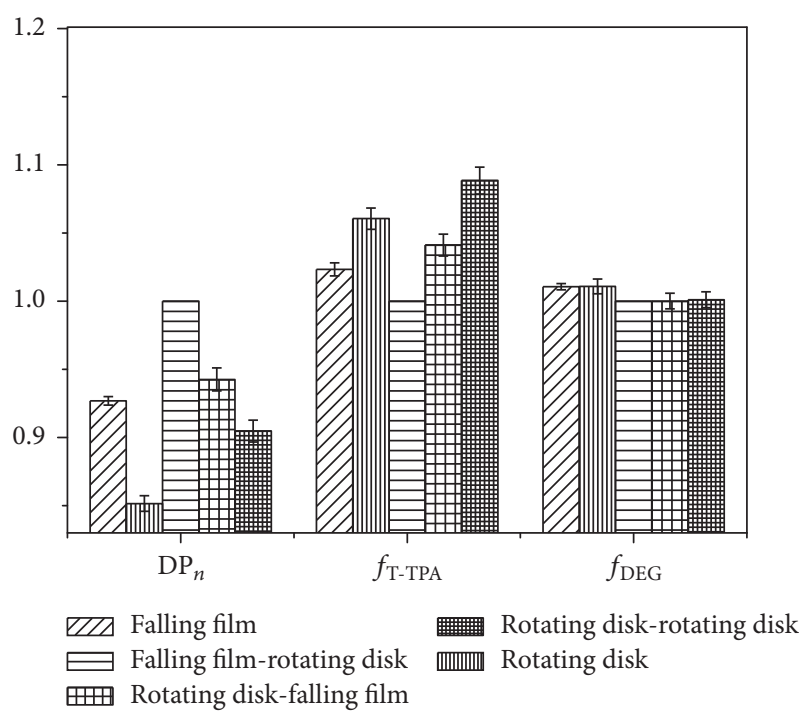

FIGURE 3: Quality indexes of PET prepared by different reactors $\left(270^{\circ} \mathrm{C} / 1 \mathrm{mmHg}\right.$ for the first reactor and $275^{\circ} \mathrm{C} / 0.75 \mathrm{mmHg}$ for the second reactor). Data from the falling film-rotating disk combined reactor is used as reference.

speed. In sum, the falling film-rotating disk combined reactor has the best ability to ensure product quality in practice. When the second reactor is falling film, it could be optimized to a hybrid one with coexisting stirring propulsion and falling film. This design concept could reduce the negative effect of thermal degradation reactions, the energy consumption, and production cost. Thus, improved controllability in operation would be achieved while ensuring a large enough gas-liquid interfacial area for removal of small molecules.

4.2. Model Validation. Although the intermediate product cannot be taken out at any time during the industrial production here, the flexible design allows samples to be obtained at the outlet of each reactor. The quality indexes at each outlet and the residence time are used to comprehensively match the model to large-scale production data from the factory. $k_{\mathrm{L}} \alpha$ is strongly linked to the reactor geometry and needs to be obtained by curve fitting the industrial data. Unlike the case of prepolymer, PET fabrics waste had suffered thermal treatments during both the original processing and initial recycling steps (e.g., friction hot forming); therefore, it has elevated $[\mathrm{COOH}]$. Further thermal degradation of PET occurs on account of the accelerating effect of high $[\mathrm{COOH}]$, leading to even higher $[\mathrm{COOH}]$. Due to the different characteristics and thermal history, the preexponential factor of thermal degradation reaction $A_{4}$ should be optimized to accommodate PET waste in our work. The following function $f$ (Equation (3)), which is the sum of errors between the model and the plant data, is minimized, where the subscripts "mod" and "pla" represent values predicted by the model and measured in the plant, respectively. The optimization results show that the model produces the best fit to the plant data when $A_{4}=6.98 \times 10^{9}$ and $k_{\mathrm{L}} \alpha=0.056 \mathrm{~s}^{-1}$ and $0.042 \mathrm{~s}^{-1}$ for reactors 1 and 2 , respectively, as shown in Table 4 . The 
TABLE 4: Quality indexes values of the falling film-rotating disk combined reactor.

\begin{tabular}{|c|c|c|c|c|c|}
\hline \multirow{2}{*}{ Quality indexes } & \multirow{2}{*}{$\begin{array}{c}\text { Feed } \\
\text { Model }\end{array}$} & \multicolumn{2}{|c|}{ Falling film reactor outlet } & \multicolumn{2}{|c|}{ Rotating disk reactor outlet } \\
\hline & & Model & Plant & Model & Plant \\
\hline $\mathrm{DP}_{n}$ & 75.07 & 83.95 & 84.07 & 91.79 & 91.92 \\
\hline$f_{\text {T-TPA }}(\mathrm{kmol} / \mathrm{h})$ & 0.1153 & 0.1054 & 0.1053 & 0.1030 & 0.1028 \\
\hline$f_{\mathrm{DEG}}(\mathrm{kmol} / \mathrm{h})$ & 0.3059 & 0.3030 & 0.3033 & 0.2994 & 0.2996 \\
\hline Residence time (min) & - & 28.83 & $25-35$ & 23.52 & $20-45$ \\
\hline
\end{tabular}

reported values of $k_{\mathrm{L}} \alpha$ are mainly concentrated in the range of $0.01-0.1 \mathrm{~s}^{-1}[27,38,39]$, verifying the reliability of our model.

$$
\begin{aligned}
f\left(k_{\mathrm{L}} \alpha, A_{4}\right)= & \sum_{m=1}^{2}\left(1-\frac{\left(\mathrm{DP}_{n}\right)_{\mathrm{mod}}}{\left(\mathrm{DP}_{n}\right)_{\mathrm{pla}}}\right)_{m}^{2} \\
& +\sum_{m=1}^{2}\left(1-\frac{\left(f_{\mathrm{T}-\mathrm{TPA}}\right)_{\mathrm{mod}}}{\left(f_{\mathrm{T}-\mathrm{TPA}}\right)_{\mathrm{pla}}}\right)_{m}^{2} \\
& +\sum_{m=1}^{2}\left(1-\frac{\left(f_{\mathrm{DEG}}\right)_{\mathrm{mod}}}{\left(f_{\mathrm{DEG}}\right)_{\mathrm{pla}}}\right)_{m}^{2} .
\end{aligned}
$$

4.3. Weight Analysis. The influences of various factors including material properties and process parameters on the $\mathrm{DP}_{n}$, $f_{\mathrm{T}-\mathrm{TPA}}$, and $f_{\mathrm{DEG}}$ of the melt from the second (i.e., rotating disk) reactor were investigated here to optimize production process to obtain the desired polymer properties and to meet different needs. The main material properties of the feed are IV $(0.45-0.6 \mathrm{dL} / \mathrm{g}),[\mathrm{COOH}](30-45 \mathrm{mmol} / \mathrm{kg})$, [DEG] (0.9-1.5\%), and catalyst concentration (0.01-0.05\%). All the variables could be converted into the parameters in our model: $\left(\mathrm{DP}_{n}\right)_{\text {feed }}=60-85,\left(f_{\mathrm{T}-\mathrm{TPA}}\right)_{\text {feed }}=0.083-0.124 \mathrm{kmol} / \mathrm{h}$, $\left(f_{\text {DEG }}\right)_{\text {feed }}=0.234-0.387 \mathrm{kmol} / \mathrm{h}$, and Cat $=0.01-0.05 \%$. The residence time in the falling film reactor is determined by the number of layers $(L=20-42)$. The effects of temperatures $\left(260-300^{\circ} \mathrm{C}\right)$, pressures $(0.1-4.6 \mathrm{mmHg})$, and residence time in the rotating disk reactor $(20-45 \mathrm{~min})$ are investigated in our study.

The parameter values under the original conditions are listed as follows: the initial material properties of the feed stream are $\left(\mathrm{DP}_{n}\right)_{\text {feed }}=75.07,\left(f_{\mathrm{T} \text {-TPA }}\right)_{\text {feed }}=0.12 \mathrm{kmol} / \mathrm{h}$, $\left(f_{\mathrm{DEG}}\right)_{\text {feed }}=0.31 \mathrm{kmol} / \mathrm{h}$, Cat $=0.025 \%$. The temperature and pressure for the falling film-rotating disk combined reactor are set at $T_{1}=270^{\circ} \mathrm{C}, T_{2}=275^{\circ} \mathrm{C}$ and $P_{1}=1 \mathrm{mmHg}, P_{2}=$ $0.75 \mathrm{mmHg}$, respectively. The initial residence time for the falling film is $L=26$ and $t_{2}=23.52 \mathrm{~min}$ for the rotating disk reactor.

4.3.1. Weight Analysis of $D P_{n}$. As seen in Figures 4(a)-4(d), the increase of $[\mathrm{COOH}]$ and $[\mathrm{DEG}]$ is beneficial for the desired reaction of ester group formation, and $\mathrm{DP}_{n}$ of the product shows good linear dependence on the $\mathrm{DP}_{n}, f_{\mathrm{T}-\mathrm{TPA}}$, and $f_{\mathrm{DEG}}$ of the feed. $\mathrm{DP}_{n}$ also increases with increasing catalyst content. It can be seen from Figure 5 that $\mathrm{DP}_{n}$ increases at first and then decreases with the increase of temperature. A higher temperature could promote the reactions of esterification/polycondensation and the removal of volatile small molecules. Within the temperature ranges of $260-275^{\circ} \mathrm{C}$ (reactor 1) and $260-270^{\circ} \mathrm{C}$ (reactor 2), a higher temperature improves $\mathrm{DP}_{n}$. Temperatures above $275^{\circ} \mathrm{C}$ for reactor 1 and $270^{\circ} \mathrm{C}$ for reactor 2 are shown to have an adverse effect on $\mathrm{DP}_{n}$, on account of the serious thermal degradation. The low pressure (high vacuum degree) could contribute to the increase of $\mathrm{DP}_{n}$, which shows a good linear relationship with $P_{2}$ (Figure 6(d)). The effect of $P_{1}$ on $\mathrm{DP}_{n}$ (Figure 6(a)) could be divided into different sections; that is, $\mathrm{DP}_{n}$ varies greatly in the range of $0.1-2.6 \mathrm{mmHg}$, and small changes could be observed at very high pressures $(\geq 3.6 \mathrm{mmHg})$. With regard to $L, \mathrm{DP}_{n}$ first increases almost linearly with the number of layers and then slows down. In the scope of our study, it is beneficial to increase the layers and residence time (Figure 7).

Above all, the weight analysis of $\mathrm{DP}_{n}$ variation results in the following equation:

$$
\begin{aligned}
& \frac{\mathrm{DP}_{n}-91.79}{91.79}=1.21 \times \frac{\left(\mathrm{DP}_{n}\right)_{\text {feed }}-75.07}{75.07}+0.19 \\
& \times \frac{\left(f_{\mathrm{T}-\mathrm{TPA}}\right)_{\text {feed }}-0.12}{0.12}+0.15 \\
& \times \frac{\left(f_{\mathrm{DEG}}\right)_{\mathrm{feed}}-0.31}{0.31}-0.19 \\
& \times \exp \left(-0.75 \times \frac{\text { Cat }-0.025}{0.025}\right)+0.34 \\
& \times \frac{T_{1}-270}{270}-13.01 \times\left(\frac{T_{1}-270}{270}\right)^{2} \\
& -0.37 \times \frac{T_{2}-275}{275}-10.72 \\
& \times\left(\frac{T_{2}-275}{275}\right)^{2}+0.039 \\
& \times \exp \left(-0.92 \times \frac{P_{1}-1}{1}\right)-3.33 \\
& \times 10^{-3} \times \frac{P_{2}-0.75}{0.75}-0.098 \\
& \times \exp \left(-0.89 \times \frac{L-26}{26}\right)+0.054 \\
& \times \frac{t_{2}-23.52}{23.52} \text {. }
\end{aligned}
$$



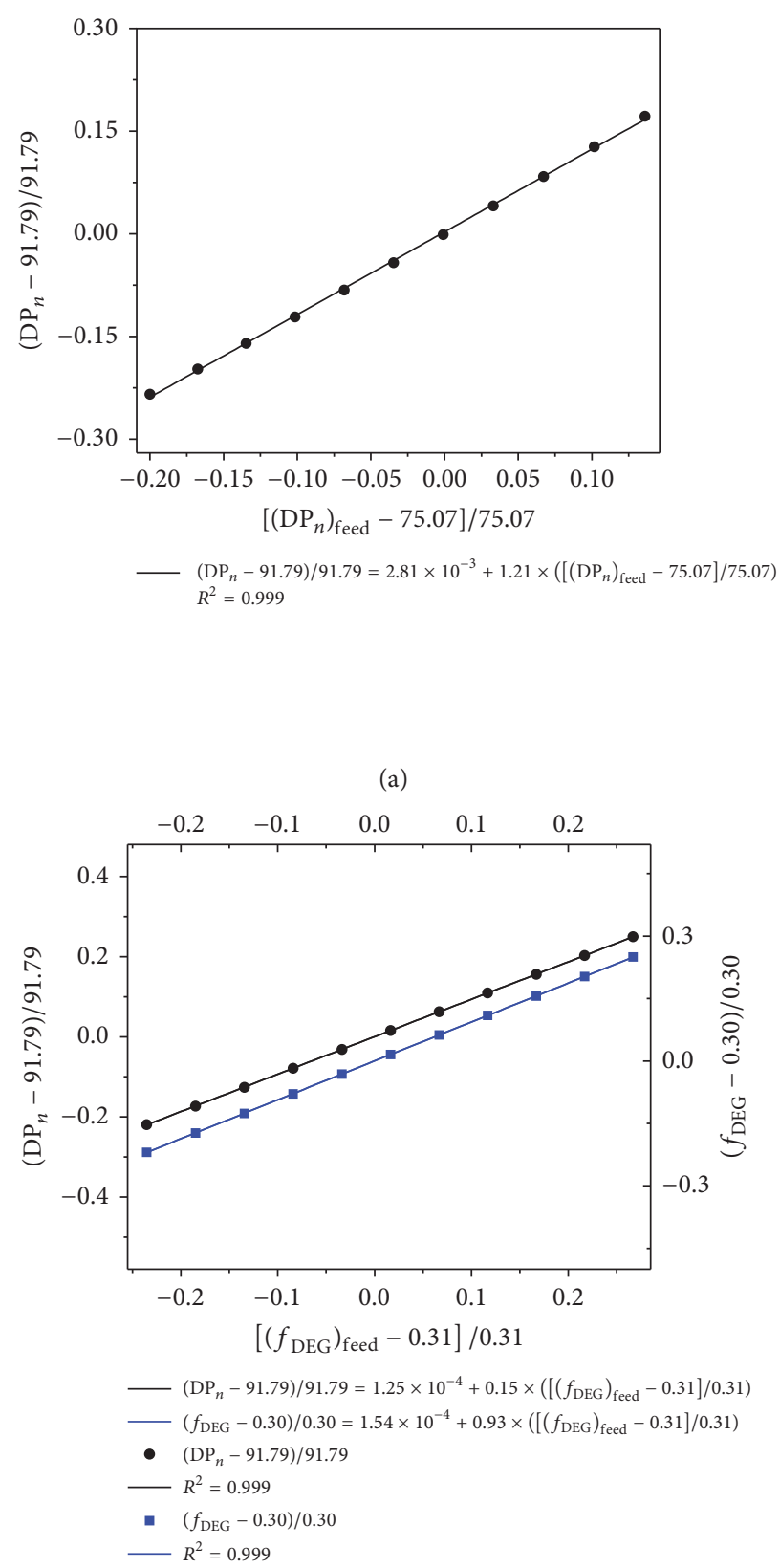

(c)

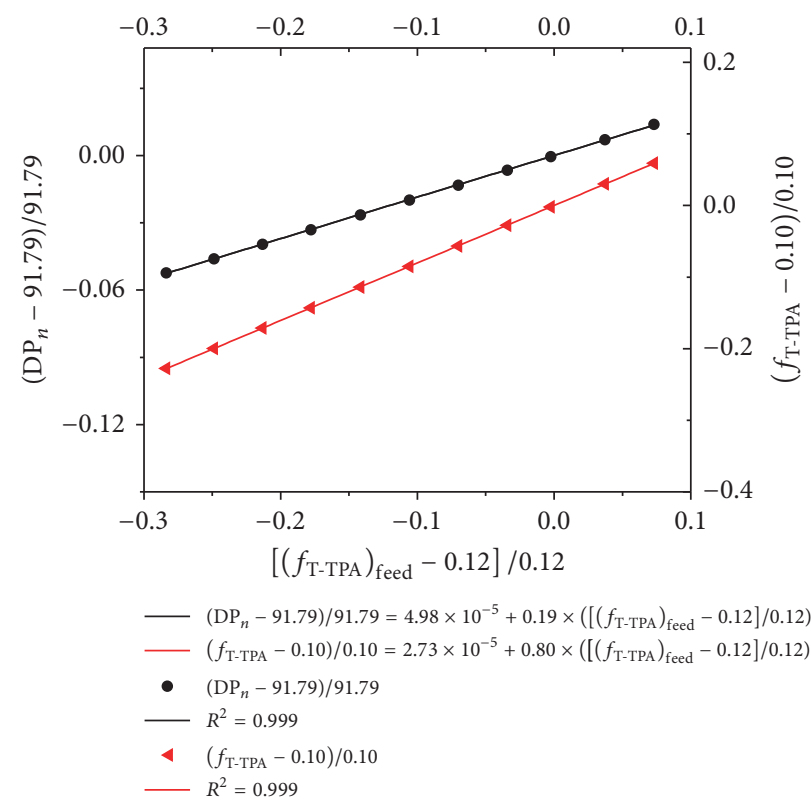

(b)

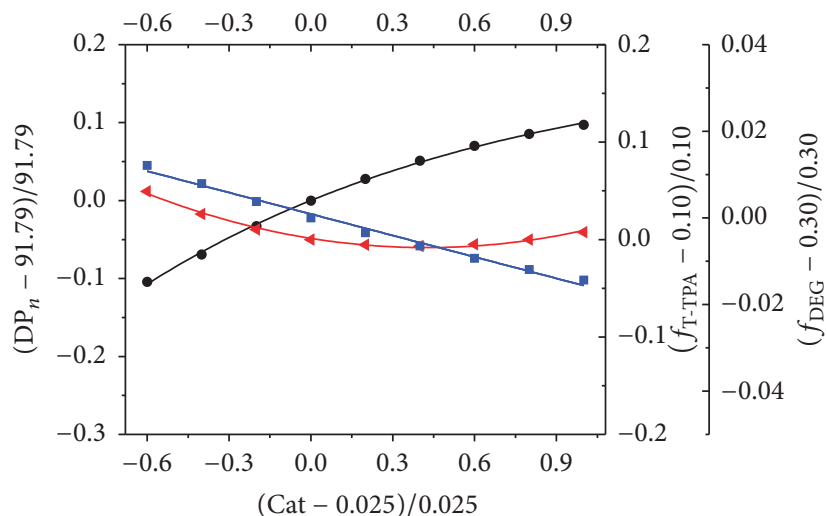

- $(\mathrm{DP}-91.79) / 91.79=0.19-0.19 \times \exp (-0.75 \times[(\mathrm{Cat}-0.025) / 0.025])$

$-\left(f_{\text {T.TPA }}-0.10\right) / 0.10=1.21 \times 10^{-3}-0.045 \times[($ Cat -0.025$) / 0.025]+0.053 \times[(\text { Cat }-0.025) / 0.025]^{2}$

- $\left(f_{\text {DEG }}-0.30\right) / 0.30=8.95 \times 10^{-4}-0.017 \times[($ Cat -0.025$) / 0.025]$

- $\quad\left(\mathrm{DP}_{n}-91.79\right) / 91.79$

$-R^{2}=0.999$

$4\left(f_{\mathrm{T}-\mathrm{TPA}}-0.10\right) / 0.10$

$R^{2}=0.991$

- $\left(f_{\mathrm{DEG}}-0.30\right) / 0.30$

$R^{2}=0.991$

(d)

FIGURE 4: Effects of feed material properties on quality indexes of liquid polymerization product. (a) Initial degree of polymerization, (b) initial carboxyl end group content, (c) initial diethylene glycol content, and (d) catalyst content.

Inadequate $\mathrm{DP}_{n}$ can severely affect the spinnability and lower the product quality. It is conductive to $\mathrm{DP}_{n}$ to enlarge the layers of the falling film reactor, increase the residence time in the rotating disk reactor appropriately, and/or lower pressure, for the products with higher requirements on $\mathrm{DP}_{n}$ (e.g., differential products). In our work, $\mathrm{DP}_{n}$ for the spinning process should stay above 88.8 to meet the requirements on the hollowness, elasticity, and filling capacity of the product intended for filling, which means that $\left(\mathrm{DP}_{n}\right)_{\text {feed }} \geq$ $72.9,\left(f_{\text {T-TPA }}\right)_{\text {feed }} \geq 0.095 \mathrm{kmol} / \mathrm{h},\left(f_{\text {DEG }}\right)_{\text {feed }} \geq 0.24 \mathrm{kmol} / \mathrm{h}$, catalyst content $\geq 0.021 \%, T_{1} \leq 287^{\circ} \mathrm{C}, T_{2} \leq 287^{\circ} \mathrm{C}, P_{1} \leq$ $2.6 \mathrm{mmHg}$, and $L \geq 18$.

4.3.2. Weight Analysis of $f_{\text {T-TPA. The initial }} \mathrm{DP}_{n}$ and $\left(f_{\mathrm{DEG}}\right)_{\text {feed }}$ have no obvious effect on $f_{\mathrm{T} \text {-TPA }}$. Therefore, only the effects of initial carboxyl end group and catalyst concentration are discussed here. As shown in Figure 4, the variation of $f_{\text {T-TPA }}$ has linear relationships with that of $f_{\text {(T-TPA)feed }}$, 


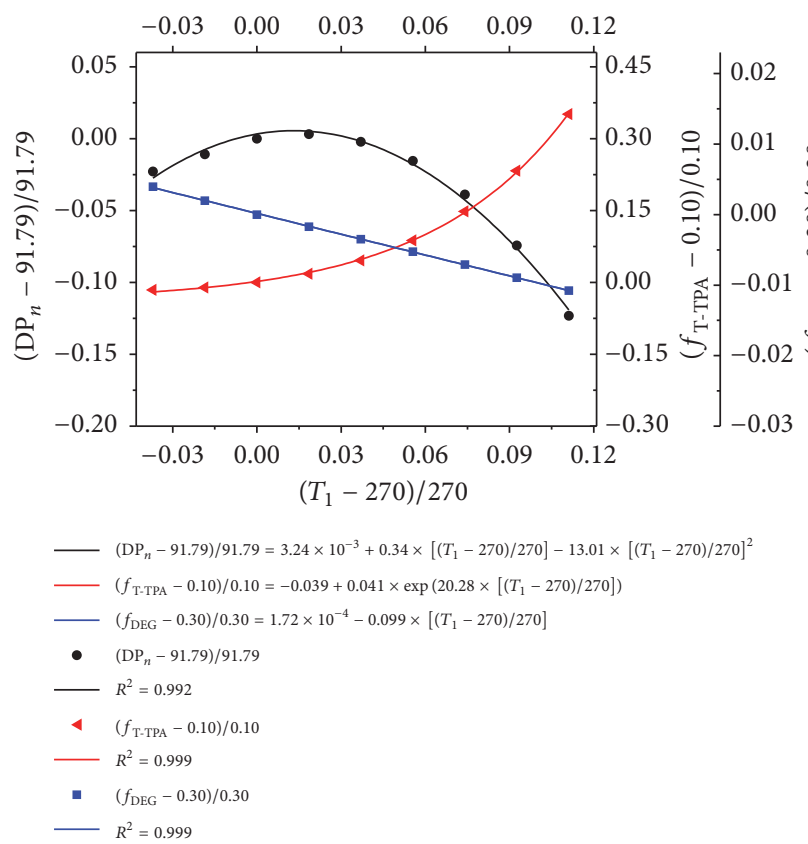

(a)

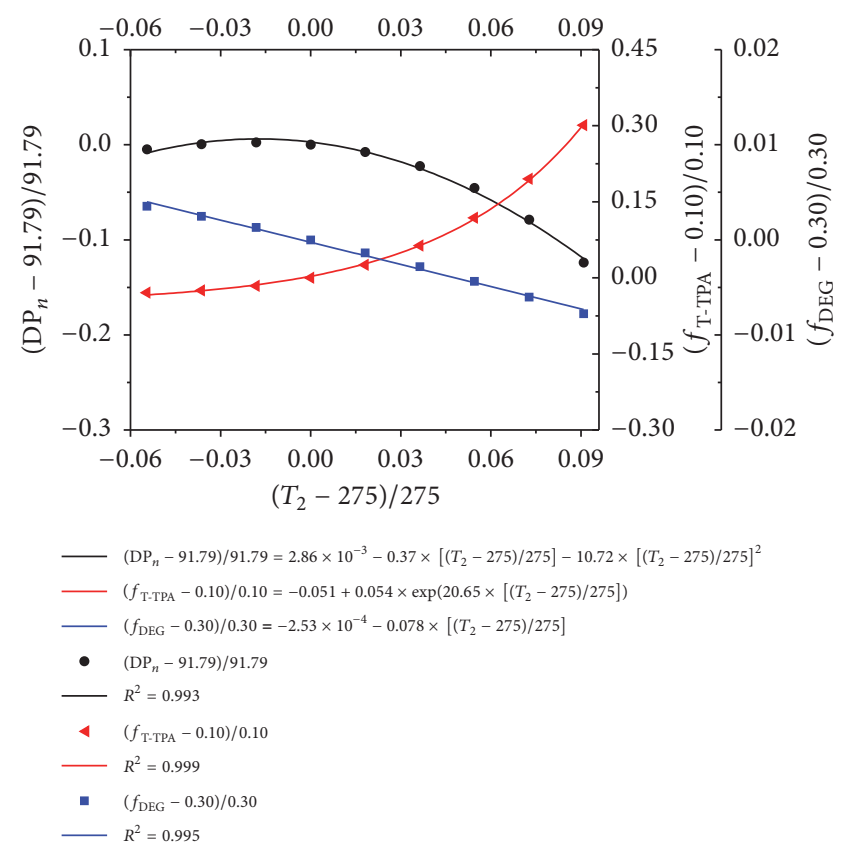

(b)

FIGURE 5: Effects of temperature in (a) falling film reactor and (b) rotating disk reactor on quality indexes of liquid polymerization product.

and increasing catalyst content in the range of $0.01-0.035 \%$ reduces $f_{\mathrm{T}-\mathrm{TPA}}$. $f_{\mathrm{T}-\mathrm{TPA}}$ also appears to increase with the temperature and decrease with pressure (Figures 5 and 6). The carboxyl end group content shows significant changes within $P_{1}=0.1-2.1 \mathrm{mmHg}$ and then remains almost constant when $P_{1}$ is above $3.6 \mathrm{mmHg}$ (Figure 6(b)). The carboxyl end group content increases first and then decreases with the increasing $t_{2}$ due to the severe thermal degradation, and the optimal residence time in the rotating disk is $32.5 \mathrm{~min}$ (Figure 7). Within the scope of this study, it is helpful to decrease the carboxyl end group content by increasing numbers of layers in the falling film reactor. In summary, the weight analysis of $f_{\text {T-TPA }}$ variation could be listed as follows:

$$
\begin{aligned}
\frac{f_{\mathrm{T}-\mathrm{TPA}}-0.10}{0.10}= & 0.80 \times \frac{\left(f_{\mathrm{T}-\mathrm{TPA}}\right)_{\mathrm{feed}}-0.12}{0.12}-0.045 \\
& \times\left(\frac{\text { Cat }-0.025}{0.025}\right)+0.053 \\
& \times\left(\frac{\text { Cat }-0.025}{0.025}\right)^{2}+0.041 \\
& \times \exp \left(20.28 \times \frac{T_{1}-270}{270}\right)+0.054 \\
& \times \exp \left(20.65 \times \frac{T_{2}-275}{275}\right)+0.014 \\
& \times \exp \left(-0.93 \times \frac{P_{1}-1}{1}\right)+3.11
\end{aligned}
$$

$$
\begin{aligned}
& \times 10^{-3} \times \exp \left(-0.15 \times \frac{P_{2}-0.75}{0.75}\right) \\
& +0.04 \times \exp \left(-0.90 \times \frac{L-26}{26}\right) \\
& -9.41 \times 10^{-3} \times \frac{t_{2}-23.52}{23.52}+0.012 \\
& \times\left(\frac{t_{2}-23.52}{23.52}\right)^{2} .
\end{aligned}
$$

The optimization of carboxyl end group concentration should be in accordance with specific applications of PET, as the differential products may have the stricter limitations on acid end group concentration, but for staple fiber, there is no strict restriction. Based on experiences from years of commercial-scale trial under the experimental conditions described here, $f_{\text {T-TPA }}$ of the PET should stay below $0.11 \mathrm{kmol} / \mathrm{h}$. Therefore, we have $\left(f_{\text {T-TPA }}\right)_{\text {feed }} \leq 0.124 \mathrm{kmol} / \mathrm{h}$, $T_{1} \leq 285^{\circ} \mathrm{C}$, and $T_{2} \leq 285^{\circ} \mathrm{C}$.

4.3.3. Weight Analysis of $f_{D E G}$. The initial $\mathrm{DP}_{n}$ and $\left(f_{\text {T-TPA }}\right)_{\text {feed }}$ play little role in $f_{\text {DEG }}$ variation. As seen in Figure 4, DEG content shows a good linear relationship with $\left(f_{\mathrm{DEG}}\right)_{\text {feed }}$ and catalyst content. A higher temperature reduces $f_{\mathrm{DEG}}$, and the opposite effect is observed for the pressure on Figures 5 and 6 . In the scope of our study, the DEG content decreases when the residence time in both reactors increases (Figure 7). Therefore, increasing the temperatures and residence time helps to reduce DEG 


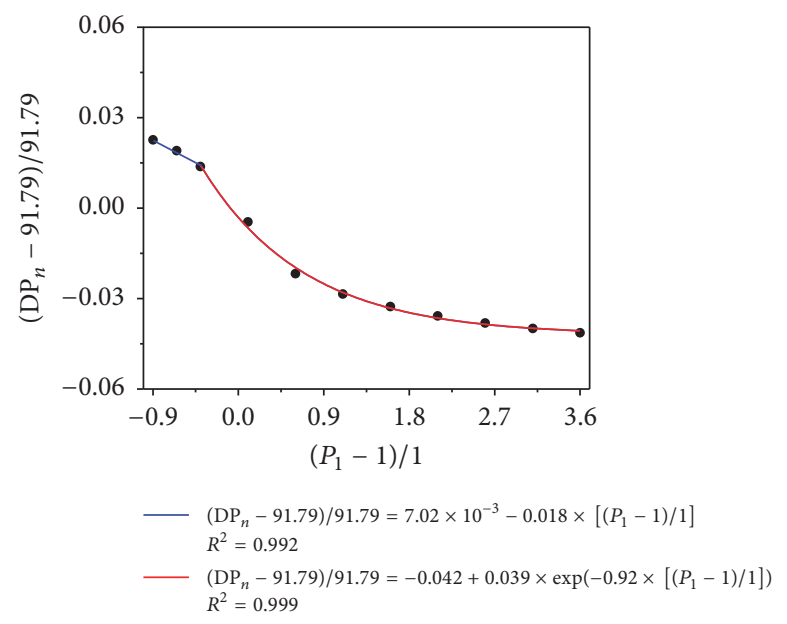

(a)

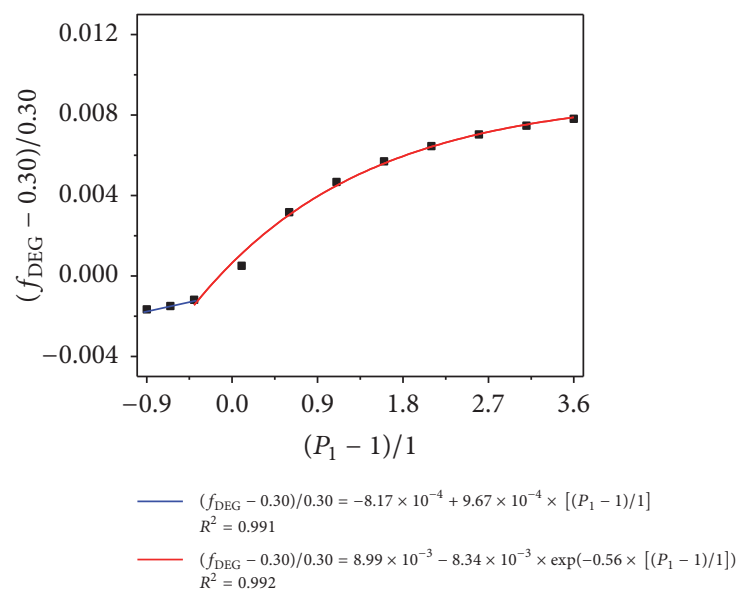

(c)

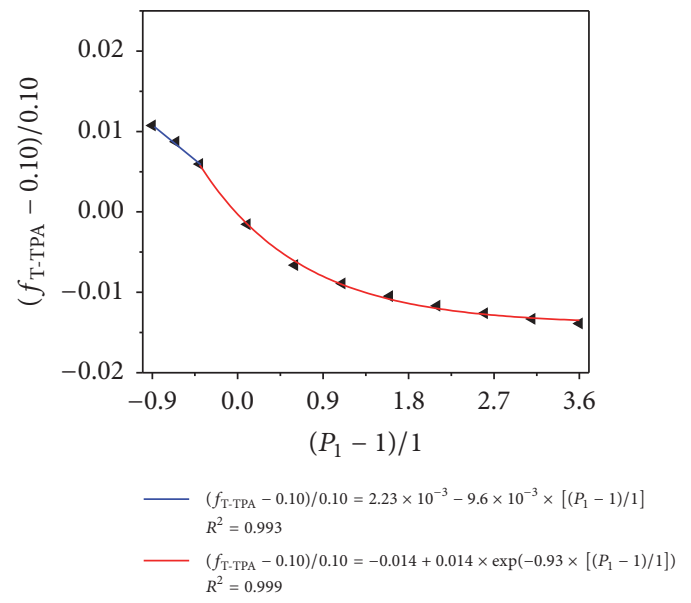

(b)
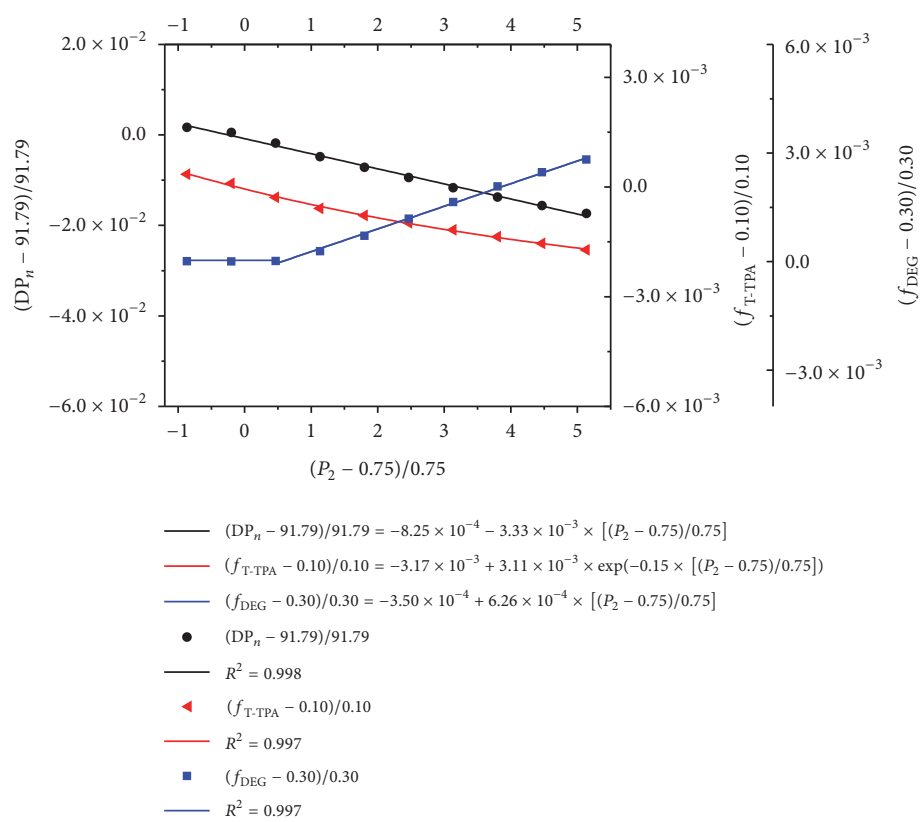

(d)

FIGURE 6: Effects of pressure in $(\mathrm{a}-\mathrm{c})$ falling film reactor and (d) rotating disk reactor on the quality indexes of liquid polymerization product.

content. An appropriate range of DEG content in PET is allowed to meet the demand for different products. The weight analysis of $f_{\mathrm{DEG}}$ variation could be listed as follows:

$$
\begin{aligned}
\frac{f_{\mathrm{DEG}}-0.30}{0.30}= & 0.93 \times \frac{\left(f_{\mathrm{DEG}}\right)_{\mathrm{feed}}-0.31}{0.31}-0.017 \\
& \times\left(\frac{\mathrm{Cat}-0.025}{0.025}\right)-0.099 \times \frac{T_{1}-270}{270} \\
& -0.078 \times \frac{T_{2}-275}{275}-8.34 \times 10^{-3} \\
& \times \exp \left(-0.56 \times \frac{P_{1}-1}{1}\right)+6.26 \times 10^{-4}
\end{aligned}
$$

$$
\begin{aligned}
& \times \frac{P_{2}-0.75}{0.75}-8.05 \times 10^{-3} \times \frac{L-26}{26} \\
& -7.88 \times 10^{-3} \times \frac{t_{2}-23.52}{23.52} .
\end{aligned}
$$

4.4. Analysis of Vacuum Extraction in Liquid-Phase Polymerization. The gas-phase vacuum extraction during liquidphase polymerization was analyzed by gas chromatographymass spectrometry (GC-MS) as shown in Figure 8. The small molecules $\left(\mathrm{C}_{14}-\mathrm{C}_{27}\right.$ aliphatic hydrocarbons) that may have been derived from degradation and several additives including plasticizers (dioctyl phthalate, $\mathrm{Di}$ (2-propylpentyl) phthalate, and dibutyl phthalate) and textile auxiliary (benzyl 


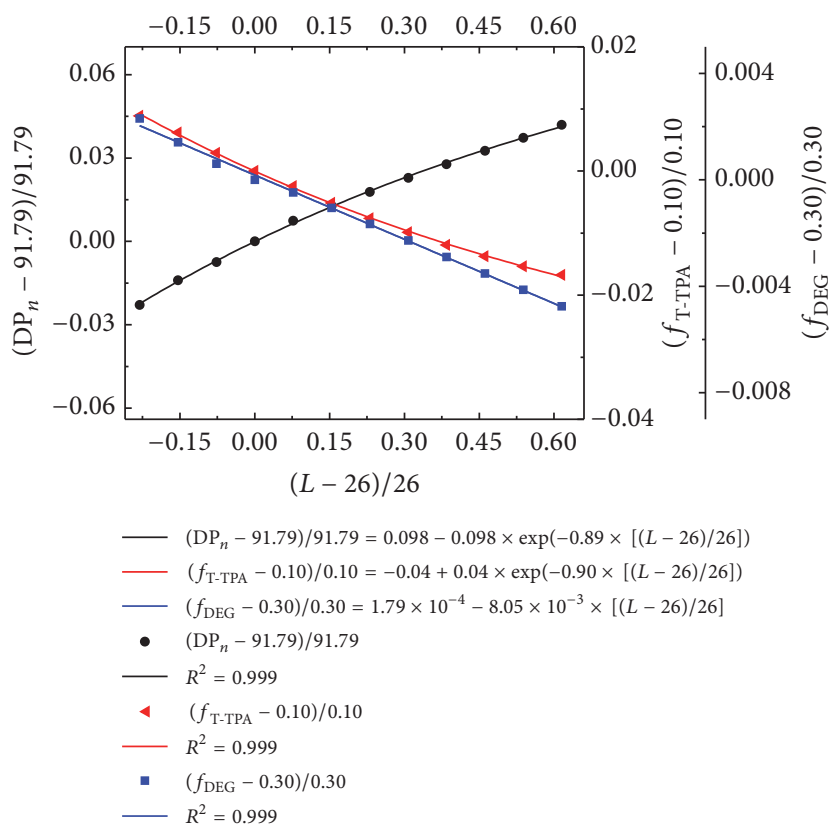

(a)

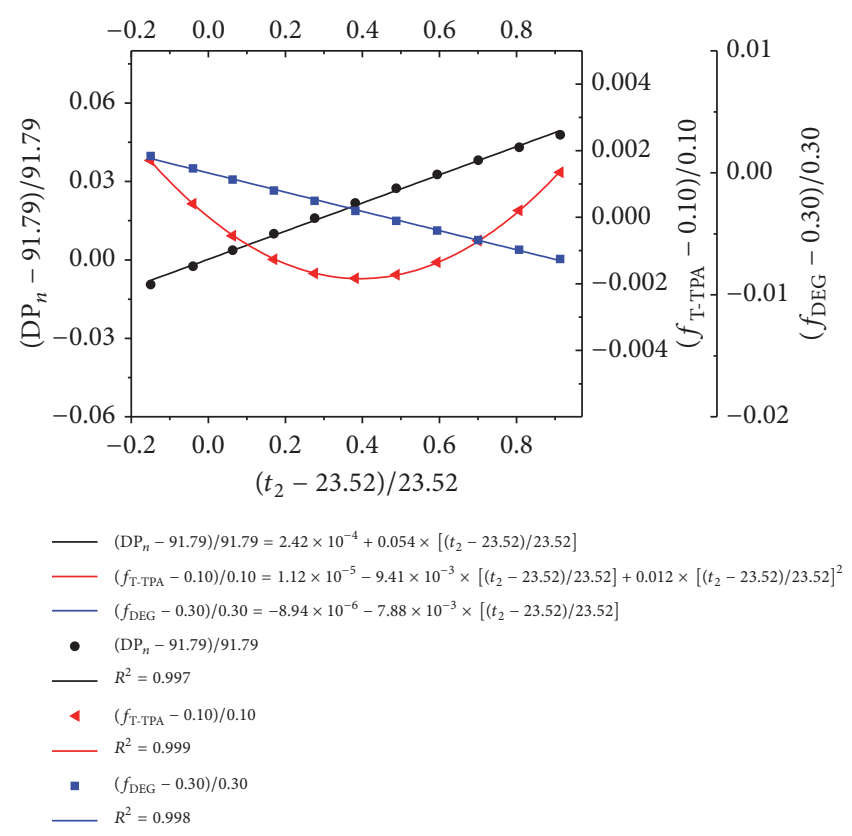

(b)

FIGURE 7: Effects of (a) number of layers in the falling film reactor and (b) residence time in the rotating disk reactor on quality indexes of liquid polymerization product.
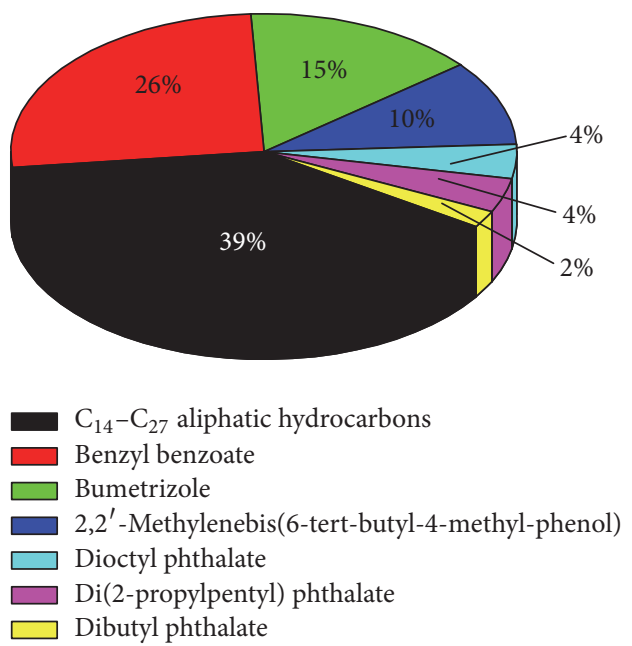

FIGURE 8: Analysis result of vacuum extraction in the liquid-phase polymerization.

benzoate, bumetrizole, and 2,2' -methylenebis(6-tert-butyl4-methyl-phenol)) were extracted from recycled PET, indicating that the purity is improved and the adverse effects on the mechanical property of recycled PET are avoided. Besides, the ecological safety of recycled PET is improved by removing some products that may have harmful effects on human health (e.g., phthalates) [40].

4.5. Performance of Recycled PET Staple Fiber. As seen in Table 4, the directly spun fiber, mainly used for nonwoven fabric and geotextile, has significantly lower qualities than the recycled PET fiber produced in this study and cannot meet the requirements for filling materials. The polydispersity index (PDI) of the recycled PET is narrower than that of the raw material and the value is much smaller than the product with SSP (2.57-2.84) and traditional horizontal reactor (2.27-2.49) [41]. In contrast, the technical indexes of the produced recycled PET staple fiber satisfy the demands for filling materials. Its quality is close to that made from bottle flakes, which has higher molecular weight (IV = $0.7-0.8 \mathrm{dL} / \mathrm{g}$ ) as shown in Table 5 .

\section{Conclusions}

A novel falling film-rotating disk combined reactor is proposed for processing PET fabrics waste, as it combines the advantages of the falling film and rotating disk reactors (large gas-liquid interfacial area and good maneuverability, resp.). Besides, the use of two reactors offers increased flexibility in actual production. In order to obtain polymers with desired properties and meet specific product characteristics in industrial production, a model was established for PET fabrics waste in the serial reactor by correcting the thermal degradation kinetics and mass transfer parameters of models previously developed for the final stage of PET polymerization. Three indexes closely related to the quality of recycled PET (intrinsic viscosity, carboxyl end group concentration, and DEG content) and the residence time were satisfactorily fitted to plant data for each of the reactors. The weight analysis of the three quality indexes was carried out based on the modeling and simulation, in order to investigate the effects of raw material qualities and operating parameters, so as to optimize the process and provide useful information for 
TABLE 5: Main performance indexes of recycled PET staple fiber $(6.67 \mathrm{dtex} * 51 \mathrm{~mm})$.

\begin{tabular}{lccc}
\hline Performance indexes & $\begin{array}{c}\text { Fabrics } \\
\text { waste }^{\mathrm{a}}\end{array}$ & $\begin{array}{c}\text { Fabrics } \\
\text { waste }^{\mathrm{b}}\end{array}$ & $\begin{array}{c}\text { Bottle flakes } \\
\text { waste }^{\mathrm{c}}\end{array}$ \\
\hline Polydispersity index (PDI) & 2.40 & 2.16 & - \\
Deviation of linear density (\%) & \pm 10 & \pm 10 & \pm 10 \\
Length deviation (\%) & \pm 10 & \pm 8.0 & \pm 8.0 \\
Curl number (per/25 mm) & $7 \pm 2.0$ & $7 \pm 2.0$ & $8 \pm 2.0$ \\
Double length fiber $(\mathrm{mg} / 100 \mathrm{~g})$ & $\leq 100$ & $\leq 30$ & $\leq 30$ \\
Defect content $(\mathrm{mg} / 100 \mathrm{~g})$ & $\leq 2000$ & $\leq 100$ & $\leq 80$ \\
Filling power $V_{1}\left(\mathrm{~cm}^{3} / \mathrm{g}\right)$ & - & $168 \pm 3$ & $175 \pm 3$ \\
Filling power $V_{2}\left(\mathrm{~cm}^{3} / \mathrm{g}\right)$ & - & $50 \pm 2$ & $54 \pm 2$ \\
Filling power $V_{3}\left(\mathrm{~cm}^{3} / \mathrm{g}\right)$ & - & $145 \pm 2$ & $145 \pm 2$ \\
Compression resilience ratio $(\%)$ & - & $\geq 68$ & $\geq 70$ \\
Hollowness $(\%)$ & - & $18 \pm 3$ & $22 \pm 3$ \\
Breaking strength $(\mathrm{cN} / \mathrm{dtex})$ & 2.6 & 3.6 & 4.2 \\
\hline
\end{tabular}

${ }^{a}$ Fabrics waste without liquid-phase polymerization. ${ }^{b}$ Fabrics waste with liquid-phase polymerization in the falling film-rotating disk combined reactor. ${ }^{\mathrm{c}}$ Bottle flakes waste without liquid-phase polymerization.

industrial production to meet different product demands. The polydispersity index (PDI) of the recycled PET is narrower than that of the raw material and the quality of recycled PET fiber is comparable to that made from bottle flakes for the purpose of filling. This model could be applied to other PET wastes and extended to investigate different aspects of the recycling process.

\section{Nomenclature}

\begin{tabular}{|c|c|}
\hline$A_{i}:$ & Preexponential factor \\
\hline Cat: & Catalyst concentration (\%) \\
\hline$C_{i}:$ & $\begin{array}{l}\text { The concentration of the segment and } \\
\text { volatile small molecule in Table } 3 \\
(i=1-10)\end{array}$ \\
\hline$C_{j}:$ & $\begin{array}{l}\text { Concentration of the volatile species } j \text { in } \\
\text { the melt }\left(\mathrm{kmol} / \mathrm{m}^{3}\right)\end{array}$ \\
\hline$C_{\mathrm{PET}}:$ & $\begin{array}{l}\text { Total concentration of the volatile species } \\
\text { in the melt at the interface }\left(\mathrm{kmol} / \mathrm{m}^{3}\right)\end{array}$ \\
\hline$E_{i}:$ & Activation energy ( $\mathrm{kcal} / \mathrm{kmol})$ \\
\hline$f:$ & Molar flow rate $(\mathrm{kmol} / \mathrm{h})$ \\
\hline$k_{1}$ to $k_{9}$ : & $\begin{array}{l}\text { Forward kinetic rate constants in Tables } 1 \\
\text { and } 2\end{array}$ \\
\hline$K_{i}:$ & $\begin{array}{l}\text { Equilibrium constants for reactions } 1,2,3 \text {, } \\
\text { and } 7\end{array}$ \\
\hline$k_{\mathrm{L}}:$ & $\begin{array}{l}\text { Overall liquid-phase mass transfer } \\
\text { coefficient }(\mathrm{m} / \mathrm{min})\end{array}$ \\
\hline$L:$ & The layers in the falling film reactor \\
\hline$P:$ & Pressure $(\mathrm{mmHg})$ \\
\hline$P_{j}:$ & $\begin{array}{l}\text { Partial pressure of volatile species } j \\
(\mathrm{mmHg})\end{array}$ \\
\hline$P_{j}^{0}:$ & $\begin{array}{l}\text { Saturated vapor pressure of volatile species } \\
j(\mathrm{mmHg})\end{array}$ \\
\hline$R:$ & Gas constant, $8.314\left(\mathrm{~J} \cdot \mathrm{mol}^{-1} \cdot \mathrm{K}^{-1}\right)$ \\
\hline$R_{i}:$ & Reaction rate in Table $3(i=1-9)$ \\
\hline
\end{tabular}

T: Temperature $(\mathrm{K})$

$t_{2}$ : Reaction time in the rotating disk reactor (min)

$x_{j}^{*}$ : Equilibrium mole fraction of volatile species $j$

$y_{j}$ : Mole fraction of volatile species $j$

$z$ : Dimensionless distance from the reactor inlet

$\alpha$ : Specific interfacial area per unit volume of the melt $\left(\mathrm{m}^{-1}\right)$

$\gamma_{j}$ : Activity coefficient of the volatile species $j$

$\theta:$ Mean residence time.

\section{Superscript \\ *: Interface. \\ Subscripts}

feed: Values of feed stream

mod: Data predicted in the model

pla: Data measured in the plant.

\section{Conflicts of Interest}

The authors declare that there are no conflicts of interest regarding the publication of this paper.

\section{Acknowledgments}

This work was financially supported by the National Key Research and Development Program (no. 2016YFB0302901).

\section{References}

[1] V. Corinaldesi, J. Donnini, and A. Nardinocchi, "Lightweight plasters containing plastic waste for sustainable and energyefficient building," Construction and Building Materials, vol. 94, article 6884, pp. 337-345, 2015.

[2] E. Langer, S. Waśkiewicz, K. M. Lenartowicz, and K. Bortel, "Application of waste poly(ethylene terephthalate) in the synthesis of new oligomeric plasticizers," Polymer Degradation and Stability, vol. 119, pp. 105-112, 2015.

[3] K. Chikaoui, M. Izerrouken, M. Djebara, and M. Abdesselam, "Polyethylene terephthalate degradation under reactor neutron irradiation," Radiation Physics and Chemistry, vol. 130, pp. 431435, 2017

[4] L. D. Poulikakos, C. Papadaskalopoulou, and B. Hofko, "Harvesting the unexplored potential of european waste materials for road construction," Resources, Conservation and Recycling, vol. 116, pp. 32-44, 2017.

[5] C. M. Pastore and P. Kiekens, Surface characteristics of fibers and textiles, Marcel Dekker, New York, USA, 2001.

[6] Y. Dang, X. Luo, F. Wang, and Y. Li, "Value-added conversion of waste cooking oil and post-consumer PET bottles into biodiesel and polyurethane foams," Waste Management, vol. 52, pp. 360366, 2016.

[7] N. E. Ikladious, J. N. Asaad, H. S. Emira, and S. H. Mansour, "Alkyd resins based on hyperbranched polyesters and PET waste 
for coating applications," Progress in Organic Coatings, vol. 102, Part B, pp. 217-224, 2017.

[8] S. Sivaram, in Proceedings of the National Seminar on Recycling and Plastics Waste Management, pp. 283-288, September 1997.

[9] V. Sinha, M. R. Patel, and J. V. Patel, "PET waste management by chemical recycling: a review," Journal of Polymers and the Environment, vol. 18, no. 1, pp. 8-25, 2010.

[10] A. Pellis, C. Gamerith, G. Ghazaryan, A. Ortner, and E. H. Acero, "Ultrasound-enhanced enzymatic hydrolysis of poly(ethylene terephthalate)," Bioresource Technology, vol. 218, pp. 1298-1302, 2016.

[11] K. Ikenaga, T. Inoue, and K. Kusakabe, "ydrolysis of PET by combining direct microwave heating with high pressure," Procedia Engineering, vol. 148, pp. 314-318, 2016.

[12] Q. Liu, R. Li, and T. Fang, "Investigating and modeling PET methanolysis under supercritical conditions by response surface methodology approach," Chemical Engineering Journal, vol. 270, pp. 535-541, 2015.

[13] Y. Yang, Y. Lu, H. Xiang, Y. Xu, and Y. Li, "Study on methanolytic depolymerization of PET with supercritical methanol for chemical recycling," Polymer Degradation and Stability, vol. 75, no. 1, pp. 185-191, 2002.

[14] A. Sangalang, L. Bartolome, and D. H. Kim, "Generalized kinetic analysis of heterogeneous PET glycolysis: Nucleationcontrolled depolymerization," Polymer Degradation and Stability, vol. 115, pp. 45-53, 2015.

[15] V. Jamdar, M. Kathalewar, R. N. Jagtap, K. A. Dubey, and A. Sabnis, "Effect of $\gamma$-irradiation on glycolysis of PET waste and preparation of ecofriendly coatings using bio-based and recycled materials," Polymer Engineering and Science, vol. 55, no. 11, pp. 2653-2660, 2015.

[16] R. M. Musale and S. R. Shukla, "Deep eutectic solvent as effective catalyst for aminolysis of polyethylene terephthalate (PET) waste," International Journal of Plastics Technology, vol. 20, no. 1, pp. 106-120, 2016.

[17] J. Zhou, M. Li, L. Zhong, F. Zhang, and G. Zhang, "Aminolysis of polyethylene terephthalate fabric by a method involving the gradual concentration of dilute ethylenediamine," Colloids and Surfaces A: Physicochemical and Engineering Aspects, vol. 513, pp. 146-152, 2017.

[18] Ç. Çam, A. Bal, and G. Güçlü, "Synthesis and film properties of epoxy esters modified with amino resins from glycolysis products of postconsumer PET bottles," Polymer Engineering and Science, vol. 55, no. 11, pp. 2519-2525, 2015.

[19] C. Wang, J. Fang, T. Liu, C. Ji, and S. Li, "Synthesis of waterborne polyurethane dispersions with glycolyzed product from pet waste: Effect of hard segment content on its properties," Polymer Science - Series B, vol. 57, no. 5, pp. 434-443, 2015.

[20] S. I. Cheong and K. Y. Choi, "Melt polycondensation of poly(ethylene terephthalate) in a rotating disk reactor," Journal of Applied Polymer Science, vol. 58, no. 9, pp. 1473-1483, 1995.

[21] S. I. Cheong and K. Y. Choi, "Modeling of a continuous rotating disk polycondensation reactor for the synthesis of thermoplastic polyesters," Journal of Applied Polymer Science, vol. 61, no. 5, pp. 763-773, 1996.

[22] Z. Xi, L. Zhao, W. Sun, and Z. Liu, "Melt polycondensation process of poly(ethylene terephthalate) in grid falling film tower," Journal of Chemical Engineering of Japan, vol. 42, pp. S96-S102, 2009.

[23] Z. Xi, L. Zhao, and Z. Liu, "New falling film reactor for melt polycondensation process," Macromolecular Symposia, vol. 259, pp. 10-16, 2007.
[24] K. Ravindranath and R. A. Mashelkar, "Modeling of poly(ethylene terephthalate) reactors: 6. A continuous process for final stages of polycondensation," Polymer Engineering \& Science, vol. 22, no. 10, pp. 628-636, 1982.

[25] K. Ravindranath and R. A. Mashelkar, "Finishing stages of PET synthesis: A comprehensive model," AIChE Journal, vol. 30, no. 3, pp. 415-422, 1984.

[26] H. C. S. Martin and K. Y. Chio, "Two-phases model for continuous final-stage melt polycondensation of poly(ethylene terephthalate). II. Analysis of dynamic behavior," Industrial and Engineering Chemistry Research, vol. 30, no. 8, pp. 1712-1718, 1991.

[27] C. Laubriet, B. LeCorre, and K. Yong Choi, "Two-phase model for continuous final stage melt polycondensation of poly(ethylene terephthalate). 1. Steady-state analysis," Industrial and Engineering Chemistry Research, vol. 30, no. 1, pp. 2-12, 1991.

[28] I. S. Kim, B. G. Woo, K. Y. Choi, and C. Kiang, "Two-Phase Model for Continuous Final-Stage Melt Polycondensation of Poly(ethylene terephthalate). III. Modeling of Multiple Reactors with Multiple Reaction Zones," Journal of Applied Polymer Science, vol. 90, no. 4, pp. 1088-1095, 2003.

[29] S. Al-AbdulRazzak and S. A. Jabarin, "Processing characteristics of poly(ethylene terephthalate): hydrolytic and thermal degradation," Polymer International, vol. 51, no. 2, pp. 164-173, 2002.

[30] V. Bhaskar, S. K. Gupta, and A. K. Ray, "Multiobjective optimization of an industrial wiped film poly(ethylene terephthalate) reactor," AIChE Journal, vol. 46, no. 5, pp. 1046-1058, 2000.

[31] B. V. Babu, J. H. S. Mubeen, and P. G. Chakole, "Simulation and optimization of wiped-film Poly-Ethylene Terephthalate (PET) reactor using multiobjective differential evolution (MODE)," Materials and Manufacturing Processes, vol. 22, no. 5, pp. 541552, 2007.

[32] D.-M. Fann, S. K. Huang, and J.-Y. Lee, "Kinetics and thermal crystallinity of recycled PET. II. Topographic study on thermal crystallinity of the injection-molded recycled PET," Journal of Applied Polymer Science, vol. 61, no. 2, pp. 261-271, 1996.

[33] C.-K. Kang, B. C. Lee, D. W. Ihm, and D. A. Tremblay, "A simulation study on continuous direct esterification process for poly(ethylene terephthalate) synthesis," Journal of Applied Polymer Science, vol. 63, no. 2, pp. 163-174, 1997.

[34] K. Ravindranath and R. A. Mashelkar, "Modeling of poly(ethylene terephthalate) reactors: 5. A continuous prepolymerization process," Polymer Engineering \& Science, vol. 22, no. 10, pp. 619-627, 1982.

[35] K. C. Seavey and Y. A. Liu, Step-growth polymerization process modeling and product design, John Wiley and Sons, Hoboken, New Jersey, USA, 2008.

[36] F. Manenti and M. Rovaglio, "Integrated multilevel optimization in large-scale poly(ethylene terephthalate) plants," Industrial and Engineering Chemistry Research, vol. 47, no. 1, pp. 92104, 2008.

[37] J. Qian, X. Q. Xing, F. H. Wang, and G. Zhang, "A kind of quenching and tempering system for waste plastics," China Patent, ZL 201020642835.4, 2010.

[38] A. Kumar, S. K. Gupta, S. Madan, N. G. Shah, and S. K. Gupta, "Solution of final stages of polyethylene terephthalate reactors using orthogonal collocation technique," Polymer Engineering \& Science, vol. 24, no. 3, pp. 194-204, 1984.

[39] S. K. Gupta, A. K. Ghosh, S. K. Gupta, and A. Kumar, "Analysis of wiped film reactors using the orthogonal collocation technique," Journal of Applied Polymer Science, vol. 29, no. 11, pp. 3217-3230, 1984. 
[40] P. Gimeno, S. Thomas, C. Bousquet et al., "Identification and quantification of 14 phthalates and 5 non-phthalate plasticizers in PVC medical devices by GC-MS," Journal of Chromatography B: Analytical Technologies in the Biomedical and Life Sciences, vol. 949-950, pp. 99-108, 2014.

[41] S. A. Jabarin and D. C. Balduff, "Gel Permeation Chromatography of Polyethylene Terephalate," Journal of Liquid Chromatography, vol. 5, no. 10, pp. 1825-1845, 1982. 

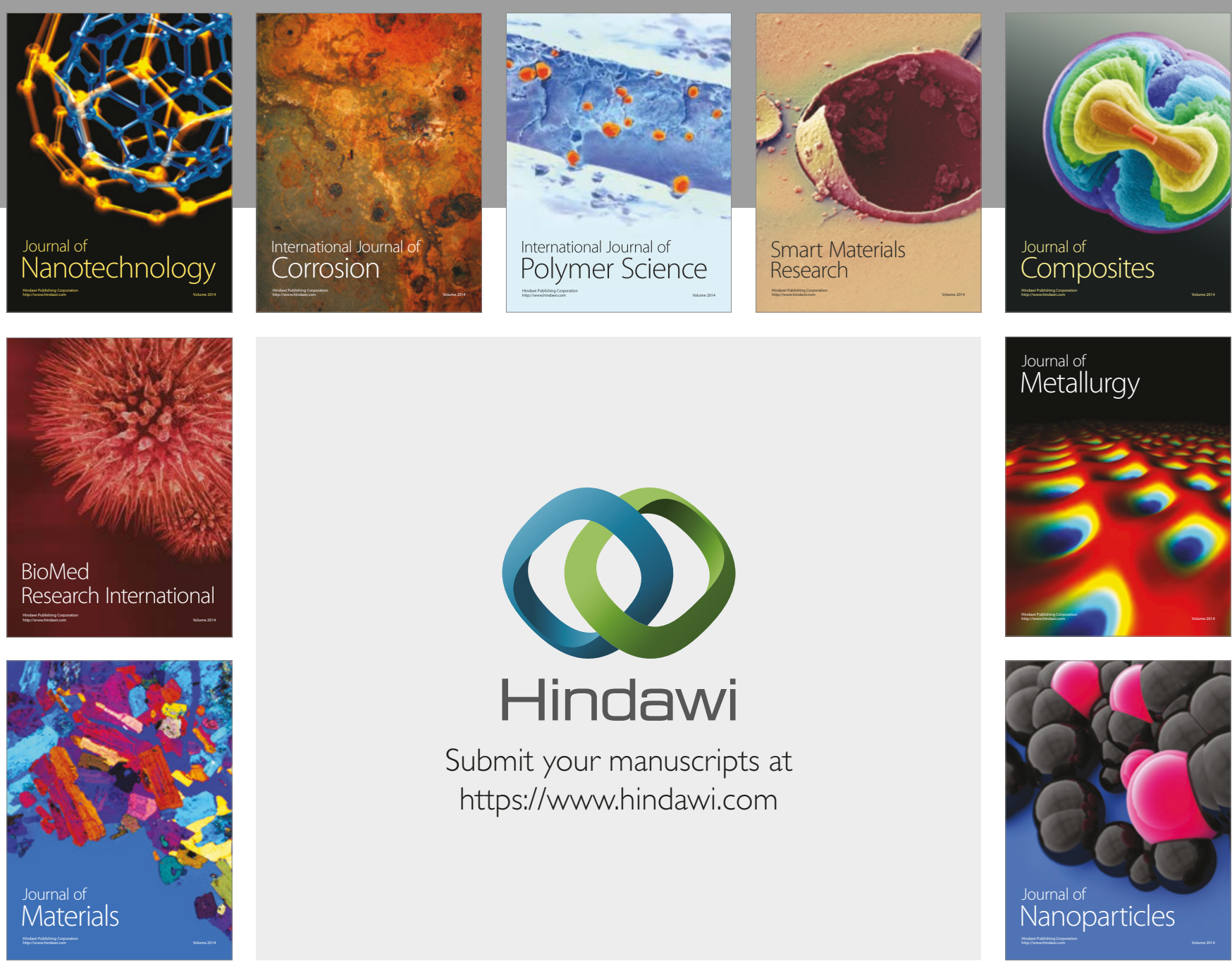

\section{Hindawi}

Submit your manuscripts at

https://www.hindawi.com
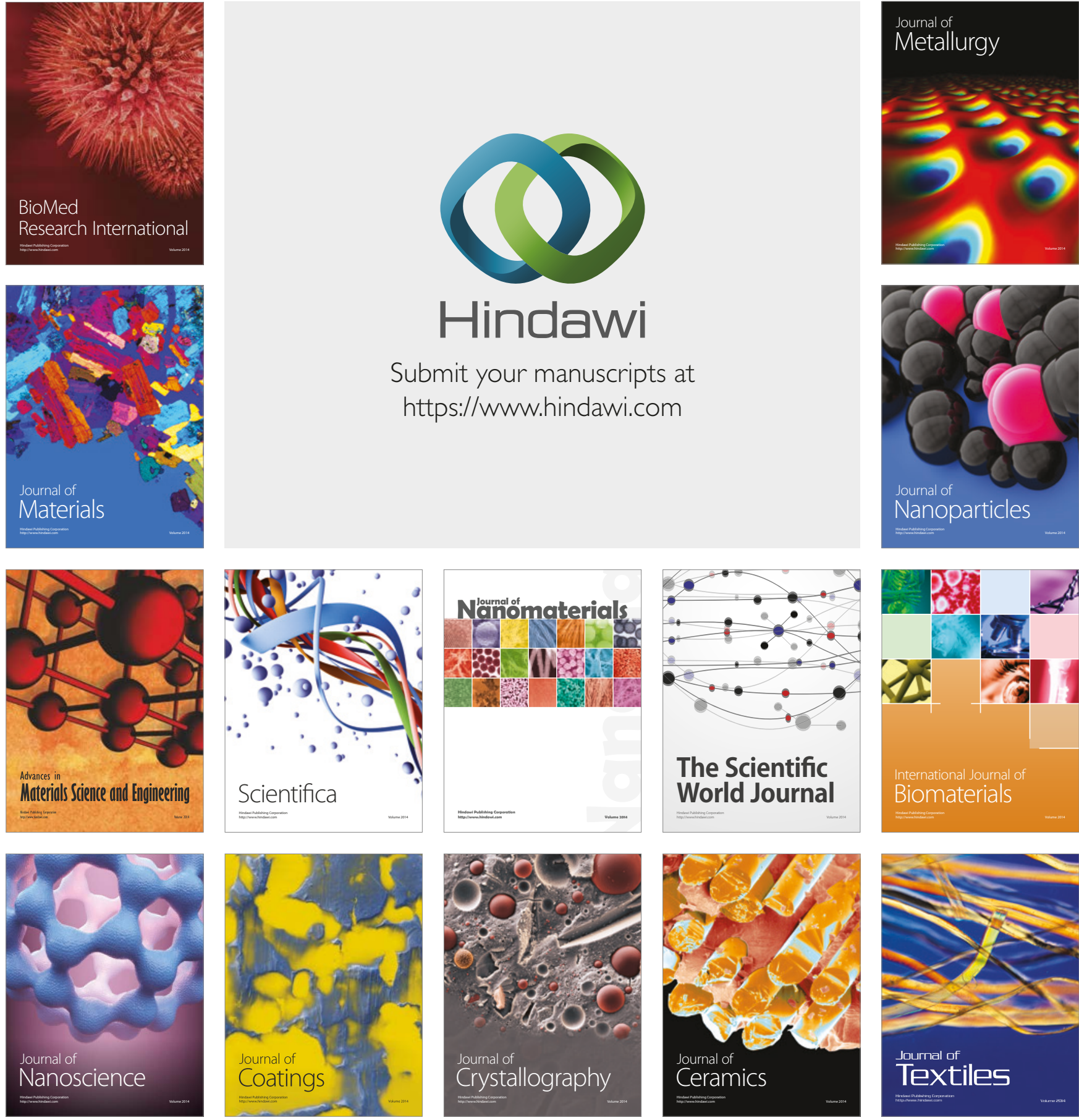

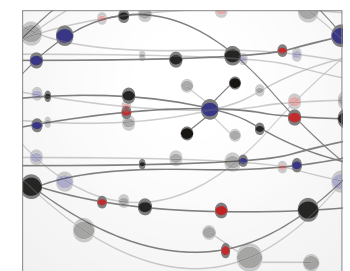

The Scientific World Journal
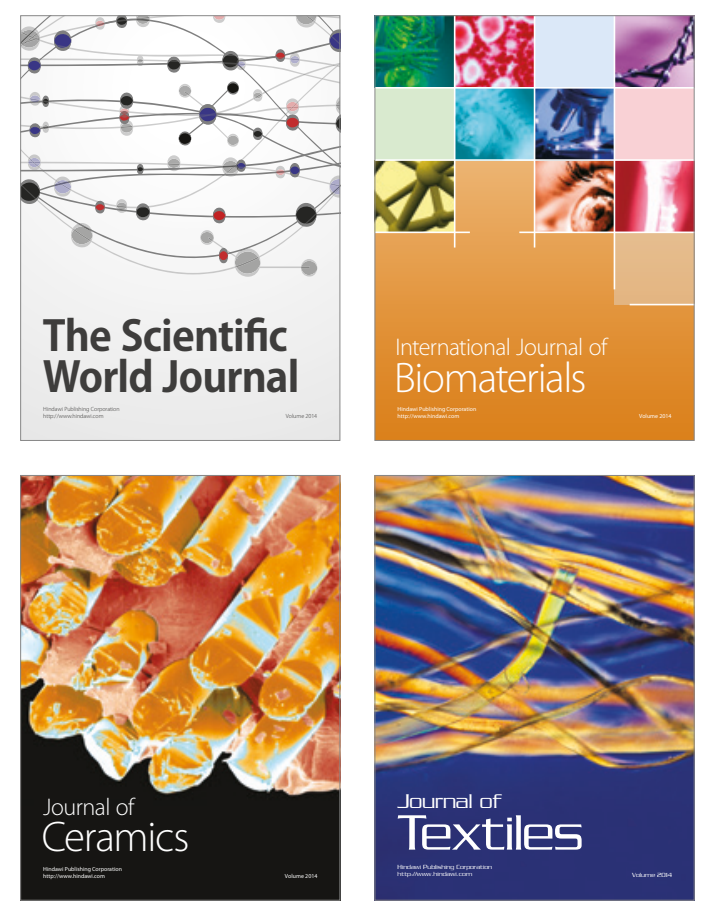